\section{New bill mandates sanctuary system for retired chimps}

In an effort to establish cost-effective 'retirement' facilities for hundreds of chimpanzees no longer needed for biomedical research, new legislation introduced in the US Congress would establish a nationwide network of sanctuaries supported by a combination of government and private funds.

But National Institutes of Health (NIH) officials are concerned that the specificity of the new legislation will restrict their flexibility in developing an effective sanctuary strategy, and are also dismayed that they were not consulted or asked about plans they have been developing since 1998-the Chimpanzee Maintenance Plan (ChiMP)—to establish long-term chimp housing.

Conserving acronyms, the Chimpanzee Health Improvement, Maintenance, and Protection (CHIMP) Act has been introduced by Congressman James Greenwood (R-PA). Under the bill, sanctuaries would be set up by an independent contractor chosen by the Department of Health and Human Services (HHS), the agency that oversees the NIH. Of the HHS budget, $\$ 30$ million would be set aside to establish and maintain the sanctuaries, and the contractor would have to obtain $10 \%$ of the funding for construction and $25 \%$ of the funding for operation of the facilities from private sources.

As a result of an aggressive breeding program in the late 1980s, the US now has a large surplus of chimps, which can live $40-50$ years. Chimpanzees no longer needed for research are now maintained in laboratory animal facilities, costing the government \$7.5 million annually. Sanctuaries, where larger groups of chimps are kept in more natural settings, are considered more humane and less expensive to operate. Public hearings on the Greenwood legislation are planned for the early part of this year.

Alan Dove, New York

\section{Israeli research must be re-directed}

Israeli doctors are devoting research time largely to clinical trials for foreign drug companies, an activity that produces no new basic research knowledge, says Dov Lichtenberg, deputy dean of Tel Aviv University's Sackler Medical School. Lichtenberg is one of a growing number of research directors from Israel's hospitals and medical schools who are asking the government to play a greater role in reversing the sharp decline in the country's basic research. He voiced his concerns at a late-November conference on the issue, organized by the Forum of Medical Research and Development Directors under the auspices of the Science and Technology Committee of the Knesset, Israel's parliament.

Bracha Rager, chief scientist of the Ministry of Health, agrees and says that the declining quality of Israel's medical research is reflected in publication data. Israel ranks 16th in the world in the number of clinical medical research publications per capita according to data from the Institute of Scientific Information for the years 1981-1995. Furthermore, Rager describes the health ministry research fund that she administers as "wholly inadequate" for the country's needs- $\$ 2$ million per annum from which to provide grants up to a maximum of $\$ 25,000$ with only a two-year commitment.

According to Gad Gilad, director of R\&D at the Asaf Ha-Rofeh Medical Center and representative of the Forum of Medical Research and Development Directors, one problem is that neither Israel's hospitals nor its public research funding bodies have specific budgets devoted to medical research. Researchers budget. science policy." may receive support from their hospital director out of discretionary funds, but no part of the hospital's budget is specifically set aside for research. Gilad is call-

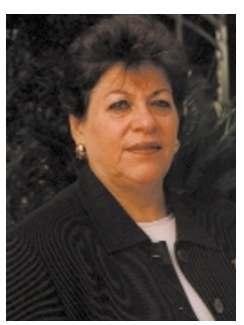
Bracha Rager ing for medical and life sciences researchers to establish a statutory national medical researchcommittee that could coordinate funding and serve as a lobby within the bureaucracy.

Ragar concurs that the low level of funding for basic research has made clinical drug trials a much more attractive activity for Israel's doctors. She claims that she needs a minimum of $\$ 30$ million a year to properly support research, and proposes that foreign companies performing drug trials in Israel be required to earmark funds for basic research.

Anat Maor, chairperson of the Science and Technology Committee of the Knesset, says that although it is unlikely that more research funds would be available in the coming year, she expects the current government's policies to bring about economic growth that will enable additional funding a year hence.

Haim Watzman, Jerusalem

\title{
Italian government reneges on research promises
}

Contrary to expectations, the Italian government's 2000 Finance Act, approved by Parliament in November, seems to have broken earlier promises to increase the country's biomedical research budget by $30 \%$ and to develop a sound national science policy. No extra money has been set apart for boosting the IL500 billion ( $\$ 270$ million) biomedical research

Instead, the Italian parliament has passed yet another a decree, according to which a oneyear overall sum of only IL11.4 billion-representing the remains of the 1998 State budget-will support four national strategic research projects in the areas of oncology, neuroscience, genetics and biotechnology.

Turin University's PierGiorgio Strata, who co-ordinates the strategic project in neuroscience, claims "Italian scientists feel betrayed, because the government still ignores the need to raise research spending from its current level of $1.2 \%$ of gross domestic product towards a value comparable to that of its European partners." Glauco Tocchini-Valentini, from the National Research Council (CNR), coordinator of the strategic project on genetics, adds "to implement an internationally competitive project we would need IL100 billion yearly instead of the IL2.5 billion established by the decree in the field of genetics."

The lack of any commitment to shake up the biomedical public portfolio in the new year is casting gloom over the reform efforts recently undertaken by the government (Nature Med. 5, 132; 1999). Strata echoes the fears of many, saying "[the lack of financial backing causes us to] doubt whether the drastic transfer of power for planning research from the CNR to the government is a serious step towards the development of a strong national

Martina Ballmaier, Milan 